\title{
Physicochemical Basis of Sulfide Technology of Iron Polysilicate
}

\author{
${ }^{1}$ Lenar N. Shafigullin, ${ }^{2}$ Linara R. Baraeva, ${ }^{3}$ Alsu A. Yusupova, ${ }^{4}$ Alexander A. Bobryshev, ${ }^{5}$ Vladimir T. \\ Erofeev \\ ${ }^{1,4}$ Kazan Federal University \\ ${ }^{2,3}$ Kazan National Research Technological University \\ ${ }^{5}$ Ogarev Mordovia State University \\ Emailimisharin_82@mail.ru; baraeva.linara@yandex.ru; alsu16rus@yandex.ru,borisov800@mail.ru,fac- \\ build@adm.mrsu.ru
}

Received: 20 ${ }^{\text {th }}$ August 2019, Accepted: $30^{\text {th }}$ September 2019, Published: $31^{\text {st }}$ October 2019

\begin{abstract}
The physicochemical basis of iron polysilicate sulfide technology is considered. Using a variety of physicochemical studies, the system of "amorphous silicon dioxide - iron chloride" was studied, not only the interaction between the components in this system with the formation of iron polysilicate was proved, but also the activating effect of the modifier on the filler. In the study of the "iron chloride - sulfur" system, the interaction of the components and the activating effect of the Lewis acid were also proved. Using the Priroda 6 quantumchemical program, the spatial structure of the interaction product was simulated in the ternary system "amorphous silicon dioxide - iron chloride - sulfur" - iron polysilicate sulfide, its stability, and strength were substantiated. Based on the results, the technology of sulfide materials is proposed. The optimal composition of the sulfide material and the optimal synthesis mode were selected. Samples of optimal composition were tested for frost resistance and resistance to aggressive environments (frost resistance of 170-180 cycles, a coefficient of stability in alkalis of $0.96-0.98 \%$, strength $70 \mathrm{MPa}$, water absorption of 5\%). The high physical and mechanical properties of the materials obtained are due to the chemical interaction of the components. Reducing the cost of synthesized sulfide materials based on silica-containing rocks of the Dobrinsk deposit and the waste of iron chloride compared to the analog - silicate concrete grade M350 amounted to $25.4 \%$ or 2611.8 rubles. for $1 \mathrm{~m} 3$.
\end{abstract}

Keywords

Iron Chloride, Amorphous Silicon Dioxide, Technology, Sulfide, Material.

\section{Introduction}

Elemental sulfur is one of the important and large-capacity types of chemical raw materials. The main consumer of sulfur is the chemical industry.

About half of the sulfur mined in the world goes to the production of sulfuric acid, whose role in the chemical industry is great. $10-15 \%$ of sulfur is used to control pests of crops, about $10 \%$ is used by the rubber industry to vulcanize rubber, as well as in the production of matches, medicines, etc. About $15 \%$ of the sulfur is sent to obtain sulfides, which are widely used in the national economy. Sulfides are the feedstock for the production of metals, as well as sulfuric acid and sulfates (FeS2).

Despite such widespread use of sulfur and its compounds, there is a steady overproduction and there is an acute question of the utilization of sulfur in the oil and gas complex [1-4]. One of the directions of expanding the application of sulfur in the production of sulfides and sulfide materials, which have several advantages, including a quick set of strength, the ability to cure at low temperatures and in the aquatic environment, the property of reuse when heated, low cost. In addition, sulfide-based materials have water resistance, weather and frost resistance, chemical resistance, low heat, and electrical conductivity and, with the appropriate feasibility study, can be used in various structures and structures.

Modern materials based on sulfur suggest only mechanical mixing of sulfur and mineral components $[5,6]$. Chemical binding of components with the formation of sulfides, in our opinion, will favorably affect the strength characteristics of the material and the environmental and sanitary safety of production.

From this point of view, it is justified to use amorphous silicon dioxide as a mineral component, which has a developed specific surface and a large number of active centers on the surface. However, to ensure the chemical interaction of the components, their additional activation is necessary. The activator may be Lewis acid, in our case, electrophilic iron (III) chloride. On the one hand, it could activate sulfur, promoting the disclosure of sulfur molecules and the formation of sulfur radicals. On the other hand, being fixed on the surface of amorphous silicon dioxide (the so-called technology of "molecular layering"), it is able to increase the activity of the mineral component.

\section{Methods}

For IR spectroscopic studies, we used the Vector 22 IR Fourier spectrometer from Bruker (Germany) (4000-400 $\mathrm{cm}-1$ ), as well as SPECORD 75 IR. 
Differential thermal analysis was carried out on a synchronous thermal analyzer STA 409 PC.

X-ray fluorescence analysis was performed on an SUR-02 Fen FV instrument, the tube voltage was $45 \mathrm{kV}$, the tube current was $400 \mu \mathrm{A}$, the recording time was $50 \mathrm{~s}$, and the irradiation area was 25 square mm.

Rheological studies were carried out by determining the time of expiration of the sulfur melt from the funnel of the viscometer.

The determination of the physicomechanical and operational properties of the obtained materials was carried out in accordance with known methods and GOSTs.

In quantum-chemical calculations, the density functional method (DFT) was used with the most widely used hybrid PBE functional implemented in the PRIRODA 6 software package basis 4, which includes relativistic corrections for systems containing a d-element and basis.in for other systems [7 -9].

\section{Results and Discussions}

Due to the fact that the ternary system "silicon dioxide - iron chloride - sulfur" is complex and presents certain difficulties for research, attempts have been made to study the binary systems "silicon dioxide - iron chloride" and "iron chloride - sulfur". Research of the system "silicon dioxide - iron chloride".

The silica gel of the KSKG brand (GOST 3956-76) was chosen as silicon dioxide for research.

The changes occurring in the IR spectra of hydroxyl groups during the interaction of a silica gel sample with iron chloride are shown in Fig. 1.

The band of $3663 \mathrm{~cm}-1$, corresponding to isolated silanol groups, is observed in the initial silica gel (Fig. 1, A 1) and disappears from the spectrum when hydrogen chloride is completely removed (Fig. 1, A 2).

In the region of $3000-1750 \mathrm{~cm}-1$ the appearance of new bands were not detected.

This fact excludes the possibility of perturbation of the silanol group due to weak interaction and confirms the entry of the functional silanol group into the chemical reaction: $\equiv \mathrm{Si}-\mathrm{OH}+1 / 2 \mathrm{Fe} 2 \mathrm{Cl} 6 \rightarrow \equiv \mathrm{Si}-\mathrm{O}-\mathrm{FeCl} 2+\mathrm{HCl}$
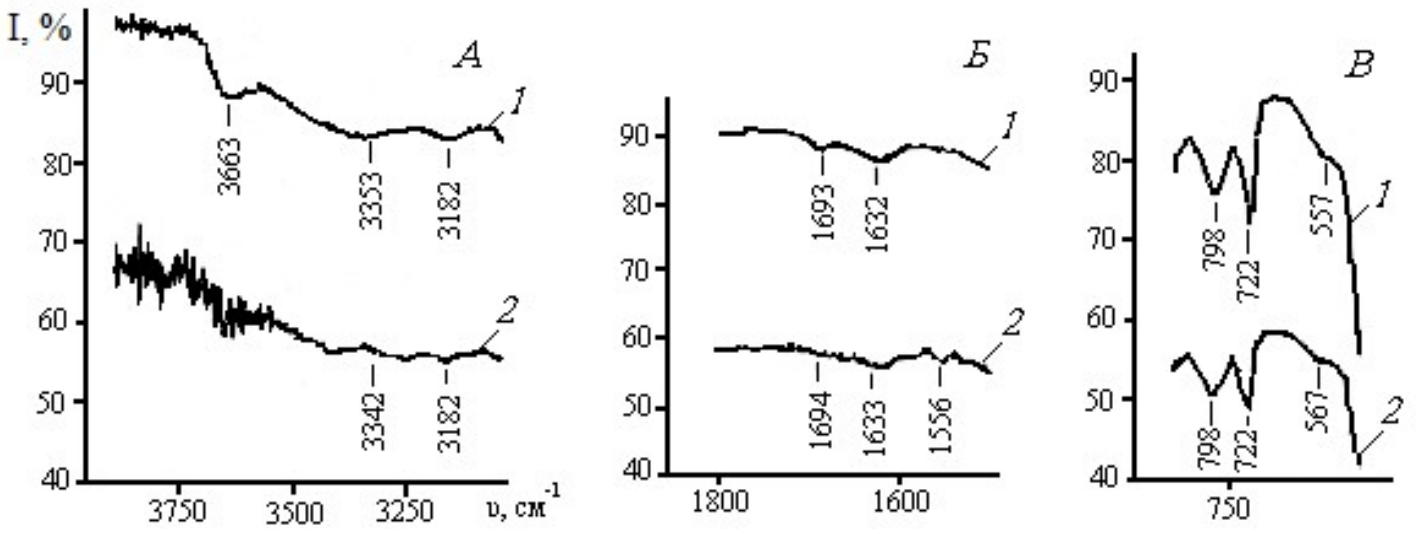

Fig. 1. IR Spectrums: 1 - Initial Silica Gel; 2 - The Silica Gel treated Iron Chloride at 200 deg. C, 1 hour

The band of $1556 \mathrm{~cm}-1$ that appeared in the spectra on a sample of silica gel treated with iron chloride (Fig. 1, B 2 ) indicates the appearance of new chemical bonds. Obviously, iron having vacant d-orbitals is also capable of forming $\mathrm{Si}-\mathrm{O}-\mathrm{Fe}$ bonds in the system under study.

In thermoanalytical curves (Fig. 2), mass loss is observed over the entire temperature range. At the first stage, physically adsorbed water is removed.

The loss of mass of the original silica gel in the temperature range $30-300{ }^{\circ} \mathrm{C}$ is $0.68 \%$ of the mass. In the second stage, at higher temperatures $\left(600^{\circ} \mathrm{C}\right)$, the mass loss is $1.78 \%$. In this case, the surface of silica gel is dehydroxylated to form siloxane bridges and is accompanied by the release of water.

When heating a mechanical mixture of silica gel with iron (III) chloride, a more intense mass loss occurs at the first stage $(2.60 \%)$ due to the release of not only water but also an additional product of the interaction of $\mathrm{FeCl} 3$ with silicon dioxide - hydrogen chloride. 


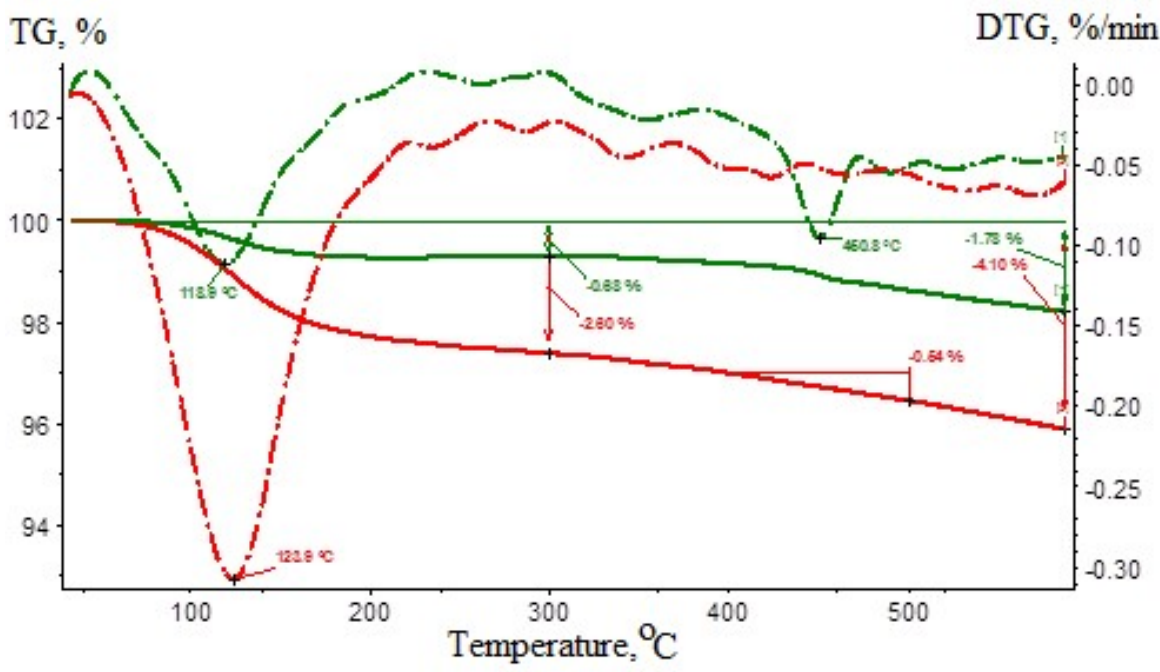

Fig. 2: Thermogravimetry and Differential Thermogravimetry for Silicon Dioxide - original silica gel

- modified silica gel

The most intense mass loss for a mechanical mixture is observed in the range of $100-200^{\circ} \mathrm{C}$; precisely in this interval, the reaction of iron chloride with silanol groups of the surface of silica gel actively proceeds [10, 11]. Further heating of the modified silica gel leads to additional mass loss, the total mass loss is $4.1 \%$ in the temperature range $30-600^{\circ} \mathrm{C}$. Moreover, there are no additional effects on the DTG curve above a temperature of $200^{\circ} \mathrm{C}$, which may indicate a strong fixation of iron chloride on the surface of silica gel with the formation of iron polysilicate - a heat-resistant complex.

The results of X-ray fluorescence analysis for the content of iron and chlorine showed that the ratio of the chlorine content to the iron content in the solid product of the interaction of silica gel with ferric chloride is less than unity. The value of suggests that when the silica gel is modified with iron chloride at $200^{\circ} \mathrm{C}$, iron is fixed mainly on three silicon-oxygen tetrahedra and the main amount of hydrogen chloride released is removed from the product, which is confirmed by thermal analysis data (Fig. 2). Thus, the reaction mainly proceeds on the surface of silica gel:

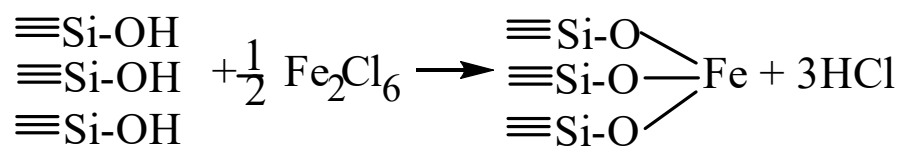

An analysis of the IR spectra of the modified silica gel in conjunction with elemental and thermogravimetric studies prove the interaction of iron chloride with silanol groups of the surface of silica gel mainly on three siliconoxygen tetrahedrons with the formation of a stable complex - iron polysilicate.

System studies and "iron chloride - sulfur."

It is known [12,13] that, depending on the temperature of the melt, the viscosity of sulfur varies over a wide range, and the properties of sulfur directly depend on its viscosity.

A comparative analysis of the viscosity of the pure sulfur melt and with the addition of a modifying additive - iron (III) chloride is presented in Fig. 3. 


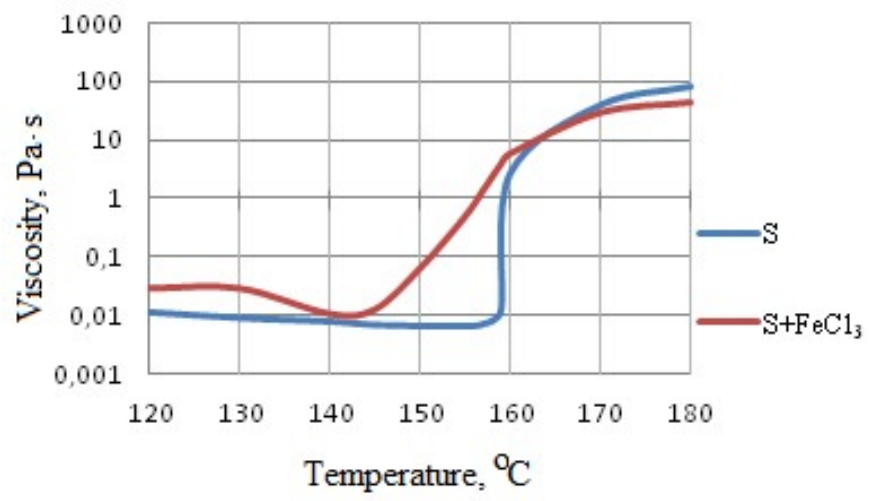

Fig. 3: Viscosity-Temperature Relation of Pure Sulfuric Melt and With the Addition of the Modificator

As can be seen from the presented dependence, when iron (III) chloride is added, sulfur polymerizes already at a temperature of $145^{\circ} \mathrm{C}$, the rings $\mathrm{S} 8$ begin to break, passing into open chains, whereas for pure sulfur this temperature is $159^{\circ} \mathrm{C}$. Therefore, the effect of iron (III) chloride is manifested by a decrease in the temperature of the onset of polymer chain formation due to the rupture of stable sulfur rings. The formation of a certain amount of "plastic" or "polymer" sulfur, which, in comparison with crystalline modifications of sulfur, has a higher deformability, tensile strength, greater adhesion to aggregates and lower internal stresses during the transition from a viscous-liquid state to a solid $(60 \%)$ will have a positive effect on the physical and mechanical characteristics of the sulfide materials obtained.

The compound obtained by the interaction of iron chloride with sulfur was identified by IR spectroscopy. New absorption bands of 345, 164 and $92 \mathrm{~cm}-1$ appear on the spectrum of the product of the interaction of sulfur with iron chloride, indicating the appearance of new chemical bonds and, consequently, the formation of a new compound [14].

Thus, the results of infrared spectroscopy prove the formation of iron sulfides in the interaction of sulfur with iron chloride.

The formation of bonds both between the binder component and the modifying additive, there and between the binder component and the modified filler contributes to the production of high-strength monolithic material.

During the interaction of silica gel modified with iron (III) chloride with sulfur, sulfides of variable composition are formed, containing both two sulfur atoms and polymer sulfur chains. The activating additive of ferric chloride acts not only as a modifier of the surface of silica gel but also as an activator of the discovery of stable cyclic sulfur molecules.
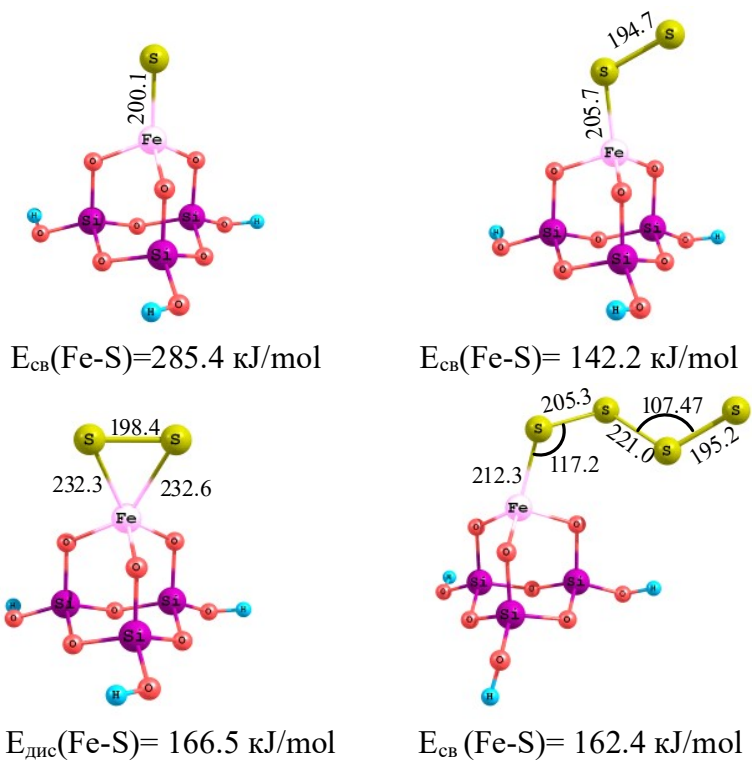

Fig. 4: Interaction Products of the Modified Silicon Dioxide with S1, S2, and S4 Sulfur 
The strongest Fe-S bond is formed by one sulfur atom (Fig. 4). When two atoms are fixed, rearrangement into a pyrite-like complex is energetically beneficial.

When two silica gel clusters are crosslinked with sulfur S4, a strong complex is formed: bond energy Fe-S 155.1 $\mathrm{kJ} / \mathrm{mol}, \mathrm{S} 2-\mathrm{S} 3101.2 \mathrm{~kJ} / \mathrm{mol}$ - in the case of the formation of a linear sulfur chain. When rearranging into pyritelike complexes on both silicon-oxygen tetrahedra, the central bond S2-S3 is significantly strengthened $(201.7 \mathrm{~kJ}$ / mol), which indicates the good crosslinking ability of sulfur, similar to crosslinking in rubbers. Iron polysilicate sulfide with two pyrite-like complexes is energetically lower than the linear structure of the sulfur chain between iron atoms by $166.09 \mathrm{~kJ} / \mathrm{mol}$, and it is likely that when sulfide material cools down, it will harden due to structural changes in iron polysilicate sulfide.

Since the silica-containing rock of the Dobrinsk deposit contains mainly amorphous silicon dioxide (68\%), the results obtained for objects based on silica gel, as we assume, should be confirmed for silica-containing rock.

Based on the results of the studies, technology has been developed for iron polysilicate sulfide from sulfur refinery waste and silica-containing rock of the Dobrinsk deposit. A step-by-step diagram of the technology is presented in Fig. 5.

Pre-ground amorphous silicon dioxide is modified with $1 \%$ iron (III) chloride at $\mathrm{T}=200^{\circ} \mathrm{C}$, the modification time is one hour. As a result, iron polysilicate is formed. Next, the modified silicon dioxide is mixed with ground sulfur at a ratio of 1: 1 . The mixture of iron polysilicate with sulfur is heated to a temperature of $140-150^{\circ} \mathrm{C}$ with constant stirring, the heating time is 20 minutes, and iron polysilicate sulfide is formed.

This technology formed the basis for the synthesis of sulfide materials based on iron polysilicate sulfide. The mixture obtained in the last stage was loaded into molds and pressed, after complete cooling, the formwork was performed.

The samples obtained have high strength (up to $70 \mathrm{MPa}$ ), low water absorption (5\%), frost resistance of 170-180 cycles, and an alkali resistance coefficient of $0.96-0.98 \%$.

An indicative technical and economic assessment of the cost of sulfide materials based on silica-containing rock and waste iron (III) chloride was carried out.

Reducing the cost of synthesized sulfide materials based on silica-containing rocks of the Dobrinsk deposit and the waste of iron chloride compared to the analog - silicate concrete grade M350 amounted to 25.4\% or 2611.8 rubles. for $1 \mathrm{~m} 3$. 


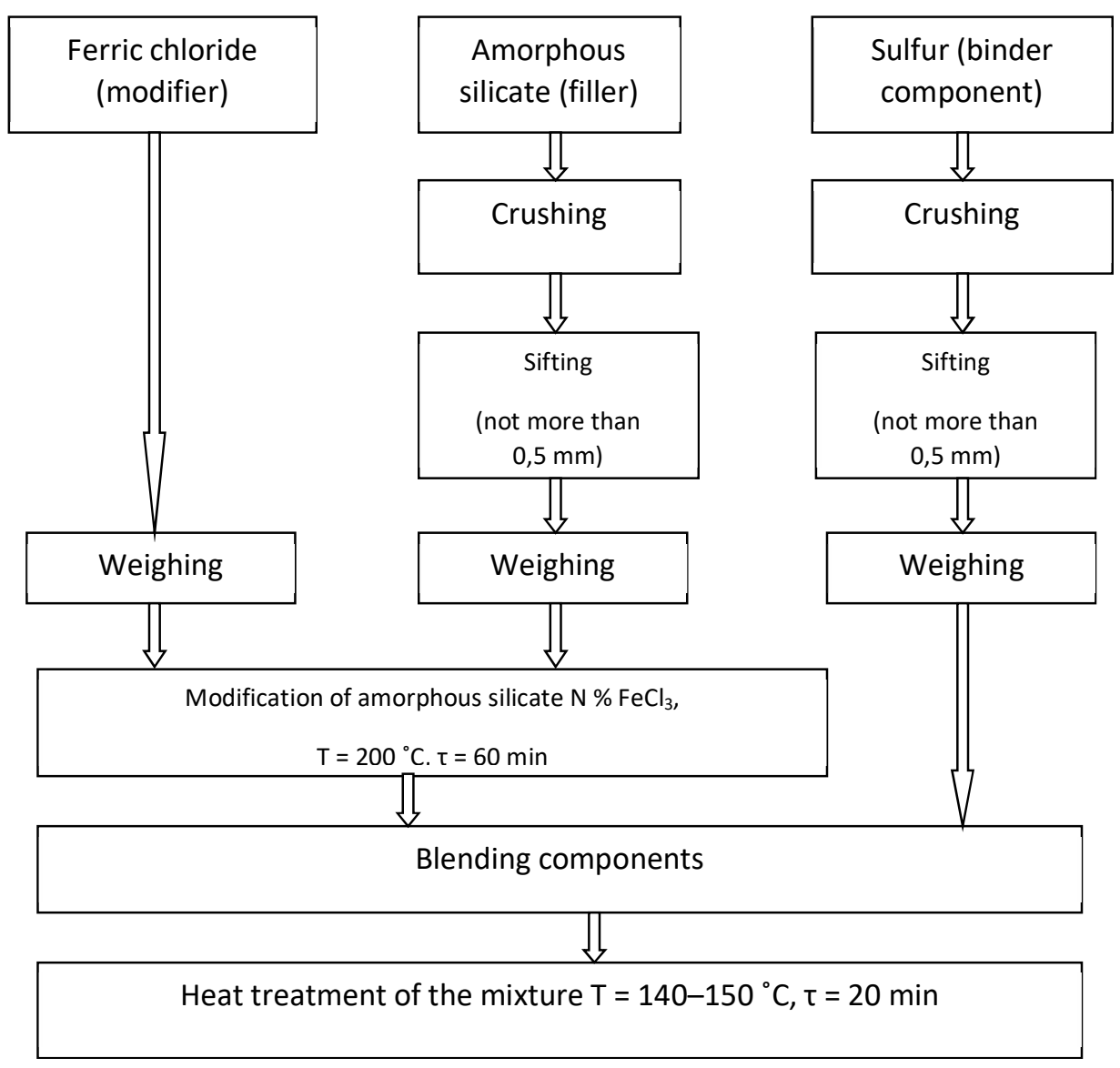

Fig. 5: Flowsheet of Sulfide Polysilicate Iron Synthesis

Given the timely complete processing of the resulting sulfur of the oil and gas complex [15-17] and the absence of the need for storage and environmental costs, the estimated economic amount will be about 2 million rubles/year (only for TANECO OJSC).

\section{Summary}

The high physical and mechanical properties of the materials obtained are due to the chemical interaction of the components. Using physical and chemical studies, the activation of iron chloride as a binder component and a mineral filler is proved. With sulfur, iron chloride forms stable sulfides of variable composition, with silicon dioxide a thermally stable iron polysilicate. Upon receipt of the sulfide material, the iron polysilicate interacts with sulfur to form iron polysilicate sulfide, which contributes to the formation of a strong uniform structure and provides high mechanical and operational properties.

\section{Conclusions}

The development of the production of sulfide materials solves not only technical, economic but also environmental problems. The cost of the materials obtained is lower than based on a cement binder, and many physical and mechanical characteristics are much higher. Based on the results of the studies, it can be concluded that the issues of integrated large-scale development of technology for the processing of industrial waste and the production of durable, chemically resistant materials will always remain relevant and in demand in the near and long term in solving both environmental and technical problems.

\section{Acknowledgments}

The work is performed according to the Russian Government Program of Competitive Growth of Kazan Federal University.

\section{References}

[1] The review of the market sulfur in the CIS: the report on the research of the current state of the market of sulfur in the CIS and to the forecast of his development. - M.: Infomayn, 2010. - $196 \mathrm{p}$. 
[2] F.R. Ismagilov Ways of ecological optimization of sulfur production at gas and oil refineries // Sera and sulfuric acid - 2017: Sat. materials of the 7th International Scientific and Practical Conference. - Moscow: JSC "Institute" GINTSVETMET ", 2017, pp. 28-31.

[3] N.N. Kislenko, Production, and consumption of sulfur in Russia. Future of new sulfur-containing production / N.N. Kislenko [and others] // Mater. Inter. conf. "Sulfur-2002", Austria, 2002

[4] N.V. Usmanov, Consumer properties of sulfur, Building materials, equipment, technologies of the XXI century. 3 (2007) 41 p.

[5] T.A. Sullivan, Sulfur in coatings and structural materials. New uses of sulfur, advances in chemistry series / T.A. Sullivan, WC McBee, DD Blue // American Chemical Society Washington DC. - 1975.-№.40. - pp. 55-74.

[6] M. Salamah, Sulfur utilization prospects in Saudi Arabia / M. Salamah // 2004 IFA Production and international and trade conference, 3-5 October 2004, Dubai, UAE

[7]J.P. Stewart, Optimization of Parameters for Semiempirical. Methods. I. Method/J.P. Stewart//J. Comp. Chem. -1989. -Vol. 10. -No. 2. - pp. 209-220.

[8] D.V. Besedin, L.Yu. Ustynyuk, Yu.A. Ustynyuk, VV. Lunin. A theoretical DFT study of the mechanism of $\mathrm{CC}$ bond hydrogenolysis in alkanes on silica-supported zirconium hydrides. Mend. Commun., 2002, 12 (5). pp. $173-175$

[9] S.J. Jenkins, Bonding and structure of the Si (001) (2*1) -Sb. Surface: Pap. ECOSS-15: 15th Eur.Conf. Surface Sci. Lille, 4-8 Sept. 1995. / S.J. Jenkins, G.P. Srivastava // Surface Sci. - 1996. - pp. 411

[10] A.A. Malygin, Adsorption on New and Modified Inorganic Sorbents, Studies in Surface Science and Catalysis / A.A. Malygin, A.A. Malkov, S.D. Dubrovenskii et al. // By ed. A.Dubrovski and VA Tertykh, 1996. V. 99. pp. 213-233.

[11] K. Possemiers, Complete description of a surface dioxide of the silicon modified by BCl3 with the help of the quantitative analysis surface / K. Possemiers, K.C. Vrancken, P. Vander Voorf, E.F. Vansaf// J. Chem. Soc. Faraday Trans. - 1995.- No. 14. - p. 2173

[12] A.A. Ysupova, The technology of utilization of sulfur-containing wastes / A.A. Ysupova, R.T. Akhmetova, L.R. Baraeva, G.A. Medvedeva, J.V. Mejevich // Materials of 6th Dubrovnik Conference on Sustainable Development of Energy, Water and Environment Systems. Dubrovnik, Croatia (SDEWES11-0607). - 2011

[13] W.A. Pryor, Mechanism of Sulfur Reaction, New York - San Francisco - Toronto - London, McGraw-Hill Book Co, 1962, 335 p.

[14] E.V. Korolev, A.P. Proshin, V.T. Erofeev, Construction materials based on sulfur, PGASA, Penza, 2003,372 p.

[15] K. Nakamoto, IR spectrums and ranges of KR of inorganic and coordination compounds / K. Nakamoto. - M $\therefore$ World, 1991 .- 269 p.

[16] L.R. Baraeva, The choice of the optimum modifying additive when receiving sulphidic composite materials / L.R. Baraeva, G.I. Tuktarova, A.A.

Yusupova, R.A. Yusupov, R.T. Akhmetova, T.G. Akhmetov // Messenger of the Kazan technological university. - 2011. - No. 17, pp. 61-63.

[17] L.R. Baraeva, Technology of sulfides with use of the activator of iron chloride / L. R. Baraeva, A.A. Yusupova, R.A. Akhmetova, T.G. Gubaidulina, N.I. Naumkina, V.A. Grevtsev, R.A. Akhmetov // Messenger of the Kazan technological university. - 2011. - No.

[18] L.R. Baraeva, Receiving polysulfides from the waste of an oil and gas complex with the use of iron chloride / L. R. Baraeva, A.A. Porfiryeva, A.I. Hatsrinov, T.G. Akhmetov, A.A. Yusupova // Magazine of ecology and industrial safety. - 2008. No. 1. - pp. 35-38. 